\title{
'It helped me sort of face the end of the world': The role of emotions for third sector climate change engagement initiatives
}

\author{
Milena Büchs ${ }^{1 *}$, Emma Hinton ${ }^{*}$, Graham Smith ${ }^{* *}$
}

\begin{abstract}
This paper examines the role that attention to emotions around climate change can play for third sector climate change engagement initiatives, an area to which the literature on such initiatives has paid little attention. It focuses on Carbon Conversations, a programme that explicitly acknowledges the role of difficult emotions and underlying values in people's engagement with climate change. While there are limitations to this approach, results show that it can help certain audiences engage more deeply with issues around climate change and carbon reduction. Important lessons can be drawn for other initiatives that aim to engage the public on climate change.
\end{abstract}

Keywords: behaviour change; carbon reduction, climate change communication; emotions; third sector

\section{Introduction}

Effective public engagement is an important part of tackling climate change: it can activate or increase concern about climate change and motivate the uptake of low carbon behaviours required to reduce emissions. Public concern about climate change can also signal greater acceptability of or even public demand for mitigation policies and low carbon technologies, thus supporting policy makers advocating action in this area.

In recent years, a body of literature has emerged that examines the role that third sector initiatives can play in engaging the public around climate change and carbon reduction. Those who have argued that third sector initiatives can increase awareness of climate change and promote low carbon behaviours have mainly explained this with reference to the role of trust vis-à-vis the third sector, group-related social norms, the role of deliberation in 'unfreezing' habits, and the promotion of self-efficacy (Georg 1999, Hobson 2003, Staats et al. 2004,

\footnotetext{
${ }^{1}$ Corresponding author m.buechs@soton.ac.uk

${ }^{*}$ University of Southampton

${ }^{* *}$ University of Westminster
} 
Middlemiss 2008, Nye and Burgess 2008, Davidson 2010, Hale 2010: 256, Heiskanen et al. 2010, House of Lords 2011: 36).

We agree that these aspects are all important for understanding the third sector's role in promoting public engagement with climate change. However, this literature has so far paid little attention to the ways in which such initiatives can address emotions around climate change and carbon reduction. We argue that this is another important dimension to understand the role of third sector (and other) initiatives working on personal responses to climate change. An emerging body of literature acknowledges the role of emotions for engaging with climate change. Here it has been argued that engagement with climate change can involve negative emotions such as:

- Fear and anxiety about possible climate change impacts (Norgaard 2006: 379-80, Dodds 2011: ch. 5, Weintrobe 2013);

- Grief related to potentially permanent damages to the natural environment and livelihoods resulting from climate change (Randall 2009, Lertzman 2013, Weintrobe 2013: 42);

- Guilt about one's own contribution to climate change (Norgaard 2006: 379, Randall 2013b);

- Helplessness related to the magnitude of change necessary to tackle the problem (Norgaard 2006: 379, 381, Heiskanen et al. 2010: 7588);

- Feeling threatened in one's 'identity and status' or feelings of loss related to personal carbon reduction involving travelling and consuming less (Randall 2009: 118).

Several studies have shown that climate change communications which appeal to emotions such as fear and shock are not always effective in promoting deeper engagement with the issues or a sustained uptake of low carbon behaviours: fear can be experienced as disempowering if people do not feel able to reduce the threat (e.g. O'Neill and Nicholson-Cole 2009, Howell 2014) (but also see Meijnders et al. 2001). In fact, some authors think that climate change scepticism and resistance to behaviour change can partly result from the desire to avoid potentially negative emotions (Norgaard 2006, Hamilton 2010: 118-33, Dodds 2011: 41-55, Weintrobe 2013).

The third sector initiative Carbon Conversations attempts to help participants engage with their emotions around climate change and as such it offers insights into the role that attention to emotional processes can play for climate change initiatives. With its focus on sharing of 
experiences and emotions, Carbon Conversations differs from other small group based third sector initiatives such as Global Action Plan's Eco Teams or Carbon Rationing Action Groups which concentrate on practical advice for personal carbon reduction. Comparisons can also be drawn to wider climate change engagement approaches, where we can broadly distinguish four different (but not necessarily mutually exclusive) types: information-based, liberal-paternalist, deliberative, and values-oriented. The 'information deficit' approach assumes that on (passively) encountering new information about the impacts of their actions on climate change, individuals will go on to dispassionately apply this to their lives. This approach has enjoyed limited success, attributed to its failure to consider the importance of psychological, social, cultural and infrastructural factors that may influence action (e.g. Owens and Driffill 2008). More recently, libertarian paternalist approaches characterised by 'nudge' theory have begun to gain traction in policymaking circles. These seek to subtly reshape the decision-making context in order to make certain choices easier or more desirable, for example by designing spaces in particular ways, making favoured options the default or highlighting their social desirability (Jones et al. 2014). In contrast, deliberative and valuesbased approaches focus more on empowering people to develop active responses. Deliberative approaches provide a means of tailoring information to local contexts and encouraging lay publics to share their expertise and become involved in developing shared definitions of problems and solutions (Owens and Driffill 2008). Values-oriented approaches seek to engage with our personal responses to change: they set out to bring to the fore our emotional investment in particular ways of living and seek to strengthen cultural values deemed necessary to support pro-environmental change (Crompton et al. 2010). With its focus on emotional engagement and aim to strengthen intrinsic motivations for change, Carbon Conversations has affinities with the latter approach.

While this article does not intend to provide a full evaluation of Carbon Conversations as a programme of activity, it draws on its practices to illustrate the significance of attention to emotional processes for third sector climate change initiatives and the challenges in addressing these complex processes fully. The analysis is based on data from [project, anonymised for review].

\section{Background}


To date, the literature has focussed on the role of social norms, deliberation, trust and perceptions of self-efficacy in explaining the potential effectiveness of group-based third sector initiatives that seek to engage the public on climate change and support low carbon practices.

Numerous authors have emphasised the role that small groups can play in developing or reinforcing new social norms around attitudes on climate change as well as environmentally friendly behaviours (e.g. Georg 1999, Staats et al. 2004, Davidson 2010, Nye and Hargreaves 2010, Howell 2012: 257). For example, in reviewing Global Action Plan's Eco Teams and two eco-villages, Georg (1999) argues that people's consumption of resources is shaped by perceptions of what others expect from them and that social norms evolve through interaction within groups. Also the wider literature on the role of groups for education and counselling assumes that group environments can help members experiment with new practices, e.g. by expressing intentions to change and gauging group responses (Whitaker 2001: 167, 187). It is assumed that this can be a helpful first step to shift practices because our practices and identities are bound up within our social networks that support 'accepted' and sanction 'deviant' practices. Early research in this area has shown that behavioural intentions expressed within group contexts are more effective than those made outside of such contexts, perhaps because these expressions create a feeling of commitment to the group (Lewin 1947: 33-7).

In a review of Global Action Plan's Eco Teams, Hobson (2003: 104-5) emphasises the role that deliberation in groups can play for bringing previously 'unconscious' habits to participants' awareness. Here she argues that once participants become aware of these habits, they are able to adopt new practices (ibid: 106-8). Also the wider literature on deliberation and 'communicative action' (Habermas 1984) emphasises that the discussion of arguments within groups under conditions of equality and freedom can change participants' beliefs and assumptions and lead to more 'rational' collective action, including more environmentallysensitive outcomes (Smith 2003). However, much of the literature on deliberation focuses on the exchange of reasoned arguments while the expression of emotions is often regarded as problematic (Barnes 2008).

Several authors also claim that trust is likely to play an important role for engaging the public on climate change. For example, Hale (2010: 256) highlights that the third sector might be in a better position than government or businesses to raise awareness and concern around climate change because it is more trusted (ibid.: 264, also see House of Lords 2011: 36). However, to date there is little empirical evidence for or against this hypothesis. 
Finally, one emotional quality that the literature has picked up on is the sense of 'helplessness' or lack of self-efficacy vis-à-vis climate change that third sector initiatives can help address, for example by providing feedback on the impact of individual or collective behaviour changes (Davidson 2010: 169, Heiskanen et al. 2010). Furthermore, it has been argued that simply coming together as a group can create a sense of empowerment and support beliefs that individual actions can add up to bigger changes (Middlemiss 2008: 86, Heiskanen et al. 2010: 7588).

These are all valuable insights. However, the existing literature on the role of third sector initiatives for climate change engagement remains limited in the attention it has paid to the broader range of emotional processes that have been highlighted in the literature on the psychology of climate change. If non-engagement with climate change and one's own contribution to it can be understood as a strategy to avoid difficult emotions, the question emerges: what role can supportive group environments play in facilitating engagement with climate change? Literature on the role of groups for personal change assumes that being involved in a group with which one identifies and within which one feels 'safe' and respected can help members express and share difficult emotions in relation to specific issues, including climate change (Brown 2011: 172, Dodds 2011: 55). Furthermore, it is assumed that the process of sharing and reflecting on emotional responses to climate change together can help people 'move forward': with group support they can face the seriousness of the problem, accept their responsibility and develop new ideas for action (Whitaker 2001: 24, 55, 187-8). It is these processes with which Carbon Conversations explicitly engages.

As such, this paper examines the ways in which Carbon Conversations can support personal engagement with climate change and discusses implications for other initiatives working in this field.

\section{Carbon Conversations}

Carbon Conversations is a third sector initiative, mainly developed by psychotherapist Rosemary Randall and building engineer Andy Brown, that aims to encourage participants to halve their carbon footprint (Randall and Brown 2013: 15). Carbon Conversations groups consist of 6-8 participants, moderated by two trained facilitators, who meet six times over a period of several weeks. The meetings are structured along themes - climate change and low carbon futures, energy in the home, travel and transport, food and water, and consumption and waste - as set out in the Carbon Conversations handbook (Randall and Brown 2013). 
Meetings consist of a mixture of input from the facilitators on specific topics, small group or in-pairs discussions and games, as well as tasks to complete at home.

From its initial development and roll out in 2005 through Cambridge Carbon Footprint, Carbon Conversations groups have since been organised in various places across the UK, including amongst others Brighton, Edinburgh, Glasgow, Leeds, London, Manchester, Norwich, Oxford and Stirling, as well as outside the UK, including Geneva and Lyon. Facilitators - many of whom have been recruited from previous participant groups - are provided with training on group facilitation and run groups on a voluntary basis. Unless funding is provided by an external agent (e.g. local authority, charity, etc.), participants pay for the Carbon Conversations handbook (currently £25) but otherwise there are no charges. In 2011, the coordination of Carbon Conversations was taken over by the Climate Outreach and Information Network (COIN); in 2013 this responsibility transferred to The Surefoot Effect in Scotland. Alongside the 'community' version of Carbon Conversations, a 'workplace' version has recently been developed and delivered across a range of organisations including universities and local councils. In 2009, Carbon Conversations was selected by the Guardian's Manchester report as one of the top '20 ideas for solving the climate crisis' (The Guardian 2009).

The Carbon Conversations approach accepts that engagement with climate change often triggers difficult emotions such as anxiety, fear, shame and guilt; that it is normal for people to experience internal conflicts between different desires, emotions and values, or between their intentions and actual behaviours; and that more radical changes in people's lives can imply (perceived) losses and 'threaten' people's 'sense of identity' (Randall 2013a: 8). Carbon Conversations also assumes that engagement with these difficult emotions and inner conflicts is necessary for people to be able to move on and change: 'When people are able to explore their feelings about the need for change and receive support and encouragement, they are much more likely to go through with something that is difficult from them' (Randall 2013a: 8).

While it accepts that not all emotions and emotional ambivalences are always (directly) expressible (see discussion in Pile 2010) and that people are differently able and willing to share them with others, Carbon Conversations assumes that engagement with emotions and emotional conflicts around climate change and carbon reduction can be supported in groups. It seeks to facilitate this through a variety of activities; for instance, the calculation of participants' personal carbon footprints, usually through an interview conducted by one of the facilitators in advance of the course, aims to provide room for discussion of emotional 
responses to the results in addition to providing a benchmark for change. ${ }^{2}$ The introductory session on climate change explores participants' emotions around climate change, including their values and motivations underpinning action against climate change. Exercises such as sharing a 'memorable meal', 'favourite or nightmare journey' or reflections on what makes a home comfortable encourage participants to engage with their emotional relationships to homes, travel and food, their practices within these realms, their associated emissions and what making changes to these practices would feel like. A series of games encourages participants to collectively discuss decision-making dilemmas in these areas, exploring difficult emotions and inner conflicts related to current practices and possibilities of change. More generally, engagement with the emotional dimension of personal carbon reduction is encouraged through the facilitation style that Carbon Conversations adopts. A ground rule which is established in the first session of each group is that discussions should take place in a non-judgemental, accepting atmosphere. The facilitator guide states: 'People need to feel safe if they are going to express what they feel. They need to see that their difficulties are appreciated and their conflicts understood' (Randall 2013a: 10).

\section{Methods}

The research presented in this paper is based on a mixed methods approach which combined an online survey with semi-structured interviews.

Between 2010 and 2012, semi-structured interviews were conducted by two interviewers with three organisers and 17 facilitators, complemented by a group interview with a further 11 facilitators, to understand Carbon Conversations' approach and gather data on facilitators' experiences.

Between May and August 2012, all Carbon Conversations facilitators were asked to distribute a survey to past participants. Since Carbon Conversations did not hold a central database of all the participants at that time, this was the only way of reaching as many participants as possible. As an incentive for taking part in the survey, participants could enter a prize draw for an AlertMe electricity monitor or a one-year National Trust membership. The survey was completed by 113 Carbon Conversations participants and covered questions on motivations for taking part, personal values and environmental attitudes, behaviour changes following participation and socio-demographic background. Taking the sale of approximately 2,000 Carbon Conversations handbooks as an indication of the total number of

\footnotetext{
${ }^{2}$ The calculator was originally developed by the Centre for Alternative Technology and adapted specifically for Carbon Conversations by Andy Brown.
} 
participants by 2012, this suggests the sample represents approximately 6 per cent of all participants. However, this is probably a conservative estimate since not everyone who bought a book will have participated in Carbon Conversations.

At the end of the survey, participants were invited to register their interest for taking part in a semi-structured interview. Of the 69 participants who had indicated interest, we recruited 26 interviewees such that they covered a good spread of survey responses on actions taken, attitudes, geographical location and income to ensure a varied sample. Semi-structured interviews with participants, lasting between one to two hours, were conducted between October and December 2012 by a third interviewer. The interviews covered participants' views on climate change, their everyday practices and changes that they had made after taking part in Carbon Conversations, as well as their views of the programme. All interviews were recorded and fully transcribed (intelligent verbatim). They were coded with NVivo by the lead author, using a bottom-up coding process where codes were developed and refined during three main phases of coding. A $£ 20$ voucher for the Centre for Alternative Technologies shop was offered to each interview participant as an incentive. Codes for quotes from interviews with Carbon Conversations participants start with ' $\mathrm{CC}$ '; those from interviews with facilitators and organisers start with ' $\mathrm{F}$ '. All participants' names have been changed to protect their identities.

\section{Findings}

\subsection{Participant characteristics}

First we provide a brief overview of Carbon Conversations participant characteristics based on the survey data since this is important for assessing the initiative's reach and potential for expansion.

Survey responses on environmental attitudes show that the majority of participants held proenvironmental attitudes. Environmental attitudes were measured using the short version of the Department for Environment, Food and Rural Affair's (DEFRA) environmental attitudes and behaviours segmentation model which includes a range of Likert-type scale statements (DEFRA provided us with this model and the algorithm for estimation in April 2012). ${ }^{3}$ Using these questions enabled us to estimate the DEFRA segments that participants fell into. Results

\footnotetext{
${ }^{3}$ These include 18 statements on environmental attitudes and behaviours from the DEFRA-commissioned Survey of Public Attitudes and Behaviours toward the Environment 2009, the questionnaire for which can be downloaded from UK Data Service. 16 of these questions are coded from 1 (strongly disagree) to 5 (strongly agree) (Q16.2-16.17 of the DEFRA survey) and two of which (Q64 and 65 of the DEFRA survey) are categorical variables with 3 and 5 answer categories respectively.
} 
show that Carbon Conversations participants represented a much higher proportion of 'positive greens' compared to the general population: 82 compared to 24 per cent. ${ }^{4}$

Correspondingly, all other segments were under-represented amongst survey participants. A much higher proportion of participants also agreed or agreed strongly with the statement 'I'd like to do a lot more to help the environment' compared to the general population: 48 compared to 8 per cent. While we cannot accurately infer the environmental attitudes that participants held before engaging with Carbon Conversations, it is safe to conclude that most of those who join hold more positive attitudes towards the environment than the general population $-\mathrm{a}$ view reinforced through interviews with organisers and facilitators.

The survey also collected information on participants' social background. Table 1 provides an overview of some of the socio-demographic characteristics of survey participants as well as those who participated in follow-up qualitative interviews. It shows that the study included a high proportion of women and people with at least a first degree, and that participants had above UK average disposable household incomes.

\footnotetext{
${ }^{4}$ This figure is based on our analysis for the DEFRA-commissioned 2009 survey, applying the algorithm for the pro-environmental behaviours estimation. It thus differs from the figure of $18 \%$ that DEFRA published in its 2007 Framework of Pro-Environmental Behaviours which is based on the 2007 survey.
} 
Table 1: Social characteristics of research participants

\begin{tabular}{|l|c|c|c|c|}
\hline & \multicolumn{2}{|c|}{ Survey } & \multicolumn{2}{c|}{ Qualitative follow-up } \\
\hline & $\mathrm{n}$ & $\%$ & $\mathrm{n}$ & $\%$ \\
\hline Female & 84 & 76.4 & 20 & 76.9 \\
\hline Under 30 & 9 & 9.2 & 3 & 11.5 \\
\hline $30-64$ & 71 & 72.5 & 19 & 73.1 \\
\hline 65+ & 18 & 18.4 & 4 & 15.4 \\
\hline England & 82 & 76.6 & 19 & 73.1 \\
\hline Scotland & 22 & 22.4 & 7 & 26.9 \\
\hline Wales & 3 & 1.9 & 0 & 0.0 \\
\hline In employment & 79 & 72.5 & 20 & 76.9 \\
\hline $\begin{array}{l}\text { Higher } \\
\text { education }\end{array}$ & 79 & 71.2 & 25 & 96.2 \\
\hline Mean income $^{7}$ & 103 & $34.9 \mathrm{~K}$ & 25 & $38.6 \mathrm{~K}$ \\
\hline $\begin{array}{l}\text { Total } \\
\text { participants }\end{array}$ & 113 & & 26 & \\
\hline
\end{tabular}

Note: The per cent figures for the survey exclude missing values. The number of respondents for the 'qualitative follow-up' interviews in the last two columns refers to Carbon Conversations participants only; it excludes organisers and facilitators.

\subsection{Changes after taking part}

The survey included five questions to capture what people took away from the course and how they evaluated it overall. Results indicate that taking part in Carbon Conversations helps people understand more about the ways in which their everyday life impacts on climate change and encourages them to take action to reduce their carbon footprint. For example, 77 per cent of participants agree or strongly agree that taking part 'made me more aware of how daily life impacts on the environment', and 78 per cent agreed or strongly agreed that taking part helped them 'take action to reduce my overall carbon footprint'. 66 per cent agreed or strongly agreed that taking part helped them be 'confident in influencing others about climate change', 50 per cent agreed or strongly agreed that taking part had helped them 'face their

\footnotetext{
5 'In employment' includes full time, part time and self-employed.

6 'Higher education' refers to having at least a first degree.

${ }^{7}$ Income is defined as disposable household income and measured in 10 bands from up to $10 \mathrm{~K}$ to $90 \mathrm{~K}$ and over. The figures in the table represent the mean of the mid-points of this banded variable. Information on income was missing for 10 of the survey responses.
} 
worries about climate change' and 93 per cent agreed or strongly agreed that they had enjoyed taking part (sample size 113).

The survey also included a question that asked whether participants had reduced their impact in relation to a range of activities and whether this change had at least partly been influenced by taking part. According to this question, 76 and 74 per cent of participants state that taking part helped them reduce their electricity and heating related fuel use respectively. 71 per cent state that participation in the course helped them reduce the impact of their diet and 55 per cent say it encouraged them to reduce the amount of goods they bought. In relation to travel an area in which practices are especially hard to shift (Davidson 2010:159-167) - 31 per cent of participants reported no change because they did not fly before the course and 30 per cent reported no change in car travel because they did not drive/have a car (both indicating a comparatively high level of pro-environmental activity prior to the course and offering further evidence that participants tend to hold more positive environmental attitudes). 39 per cent of participants state that taking part in Carbon Conversations played a role in their reduction of car travel and 35 per cent report this was the case for reducing the number of flights they take. This leaves roughly another third of participants who drive and/or fly, but did not make any changes (sample size 113).

In interpreting these results we recognise that we cannot claim that our sample is representative of Carbon Conversations participants as a whole and that the survey only captures self-reported rather than measured behaviour changes. Since people who enjoyed Carbon Conversations may have been more likely to respond to the survey, it is possible that positive responses are over-represented.

We also tested whether emotional engagement was related to practice change after the course using a test for ordinal data. For this purpose we created a variable that represents the number of areas for which participants had stated they had engaged in practice change and that this had at least partly been influenced by the course. A breakdown of this variable is provided in table 2 . The extent of emotional engagement facilitated by the course was represented by a five-point scale variable indicating how much respondents agreed that participation had helped them 'face their worries about climate change'. Spearman's rho for the correlation of these two variables is 0.31 , significant at the 1 per cent level which means that greater emotional engagement around climate change is correlated with greater practice change following the course. 
Table 2: Number of areas in which participants made changes to reduce emissions, influenced by Carbon Conversations

\begin{tabular}{|l|c|c|}
\hline $\begin{array}{l}\text { Number } \\
\text { of areas }\end{array}$ & $\mathrm{n}$ & $\begin{array}{c}\text { per } \\
\text { cent }\end{array}$ \\
\hline 0 & 11 & 9.7 \\
\hline 1 & 11 & 9.7 \\
\hline 2 & 15 & 13.3 \\
\hline 3 & 16 & 14.2 \\
\hline 4 & 24 & 21.2 \\
\hline 5 & 14 & 12.4 \\
\hline 6 & 8 & 7.1 \\
\hline 7 & 14 & 12.4 \\
\hline & & \\
\hline Total & 113 & 100 \\
\hline
\end{tabular}

Note: Data are based on the online participant survey

\subsection{The role of emotions in Carbon Conversations}

Qualitative data from the interviews provide further insights into the role that emotions play within Carbon Conversation's work on climate change engagement.

First, the interview material confirms that many participants experienced difficult emotions when they found out more about climate change. For example, Fiona speaks about her reaction when she came across a graph picturing the historical development of global carbon emissions in a textbook that she used to provide private tuition:

'In the textbook there was a curve with carbon dioxide in the atmosphere and (...) I looked at it and I thought, "Shit, that's really bad news, (...) that's really, really, really concerning if that's what's really happening”. (...) It's very depressing (...). So I was... you know, I was struggling with it psychologically, ... massively struggling with, "What does this mean? Why aren't we doing anything about it? Why am I so ignorant when I'm formally a highly educated person and also like to consider myself well-informed?" you know, "This is awful”" (Fiona, CC-21).

Fiona vividly describes the painful feelings she was experiencing - especially the shock related to the scale of the problem and bewilderment that she had not engaged with it earlier. 
Apart from two participants, all the other interviewees articulated worries and fears in relation to climate change.

The interview material also illustrates how expressing and sharing difficult emotions in a group can facilitate deeper engagement with climate change and carbon reduction. For example, Lynn (CC-6) mentioned that Carbon Conversation 'gave me a space to have a talk about it [climate change]' and helped 'taking a big scary thing and facing it together'. Similarly, Peter (CC-3) stated that before participating in Carbon Conversations he had 'never really (...) seriously ... taken the time to think about climate change' and that Carbon Conversations 'helped me kind of be aware of it', while Norman (CC-10) explains that Carbon Conversations helped him to 'feel more in touch with' climate change, rather than it 'just being a vague background worry that you sort of feel you cannot attend to'. He even stated: 'this sounds a bit grand but maybe being involved in ... Carbon Conversations ... helped me sort of face the end of the world, if you know what I mean' (Norman, CC-10). These can be taken as examples that the group discussions helped participants engage more deeply with climate change, partly because it enabled them to face some of the difficult emotions emerging in this process.

Several participants explicitly stated that they valued the opportunity in Carbon Conversations to express and share difficult emotions around climate change as something that other initiatives often do not offer. For example, Janet explains:

'I think one thing that Carbon Conversations does that a lot of other organisations or other campaigns don't do is it actually recognises and addresses the psychological fear of climate change (...), it recognises that it's a scary fear and maybe that's why people are burying their heads, and this is a good way of just letting people talk about it' (Janet, CC-22).

Melanie, who had helped another initiative screen climate change films, reflects on the 'depressing' feelings that these films can sometimes leave viewers with and notes that this can deter them from engaging further with the issues:

'People would come out of these films, some of them, and they would be saying, 'Oh my God, I'm so depressed,' and you never see them again because it's all too much. And I think that was one thing that was good about Carbon Conversations I think, is that actually trying to deal with that side of things' (CC-24). 
This material suggests that having a supportive group within which feelings such as fear, anxiety, shock, frustration, sadness about climate change and our personal contribution to it are expressed can help some people 'open up' to engage more: what others express can help reflect on and face up to one's own (inner) experiences.

While this seems to have been the case especially for those who had not engaged with climate change to a great degree before the course, it is less apparent for participants who had a long history of engagement. For example, Monica (CC-2) 'felt as though I knew it all!'; and Ruth (CC-7) stated "Honest answer, no, I don't think so" when asked whether taking part in Carbon Conversations had changed any of their views on climate change or personal responsibility. However, their interviews suggest that sharing thoughts and emotions on climate change can still support participants who have extensively engaged with climate change in that they felt supported and the legitimacy of their actions reinforced by a group. For example, Monica (CC-2) agreed Carbon Conversations had 'helped me to deepen that journey' to reduce her carbon footprint and Ruth (CC-7) found it 'reinforced certain areas' for her and 'prompted me to think about what is important in life'. Several participants also described 'sharing worries' as something positive, for example as reassurance that 'you're not alone' with these worries (Norman, CC-10) or even as a feeling of 'relief of finding other people who were similarly worried' as she had got 'hardened to it' over time (Laura, CC-8). Others reflected on the encouragement they experienced by joining a group of 'like-minded people', for example Olivia who explained taking part 'helped me face some of my worries in the sense that I knew that each week I had this community of people that I'd go and discuss [with] (...), it was just more having that support system' (CC-19).

Our material also confirms claims made by other authors regarding the role that group processes can play in addressing feelings of helplessness (e.g. Middlemiss 2008: 86, Heiskanen et al. 2010: 7588). As Laura put it, Carbon Conversions 'is empowering. I feel more in control' (CC-8) or as Abbi (CC-12) remarked: 'Carbon Conversations (...) gives you a way (....) to be less scared; (...) You stop feeling powerless; (...) it gives you back some agency'. Referring to the aggregate impact of personal action, Sara (CC-18), who was less sure about the role of personal action before taking part explains how meeting others enabled her to attach greater importance to her own behaviour: 'it was quite nice to know that there was other folk doing lots of things. (...) So yeah, I think that's why I've kind of decided that yes, I could do something to make a difference, hopefully'. For some, addressing feelings of 
helplessness seemed to go beyond making them as individuals feel more able to act on climate change and make a difference (as the theory of self-efficacy suggests) but also strengthened intrinsic motivations to act. For instance, Monica (CC-2), who had already considerably reduced her carbon footprint before the course, explains that Carbon Conversations gave her 'more confidence to do stuff anyway', even if she could not be sure that these actions in themselves make a significant contribution to cutting emissions.

The interviews also show that supportive group environments can help people acknowledge inner conflicts in relation to personal carbon reduction, which several authors regard as an important step in processes of personal change (Whitaker 2001: 55, Randall 2013a: 7-8). One of many examples is Janet, who says taking part in Carbon Conversations made her become more aware of inner conflicts in relation to consumption:

'I'm materialistic not in the sense that, you know, I like brands and stuff, but I get very attached to things and I put a lot of value in things, (...) they represent my personality (...). I sort of have this internal struggle, "Do you really need it?" "No". "Then don’t buy it". "But I really want it" (...). So I guess I struggle a bit with waste and consumption in terms of guilt and just maybe getting over ... those social concepts that what you wear is who you are' (Janet, CC-22).

On the survey, Janet states that she changed the amount of goods she buys and that this was at least partly influenced by taking part in Carbon Conversations. While she explains in the interview that she still 'struggles' with reducing her consumption she states that Carbon Conversations 'definitely made me question my values':

'I'd like to break out of that mentality [that someone 'is' what they 'wear or own']. I would like it not to matter as much, I would like to feel confident that I could go out wearing a tracksuit and people would still see beyond that' (Janet, CC-22).

Laura (CC-8) - who had gone on to facilitate Carbon Conversations groups - reflected on the question of why sharing inner conflicts in a group might help participants to try out new behaviours and concluded that once participants 'speak frankly and they share their frustrations and worries and feelings about these things', suggestions for alternative actions often fall onto 'fertile ground'.

Our material also suggests that it often helps participants to 'negotiate' their internal conflicts and take up new behaviours if they are able to connect to values that support these behaviours 
(as suggested by the 'values and frames' approach, see Crompton et al. 2010). One of the facilitators described her experience as follows:

'So in examining how they feel about something materialistic like three foreign trips a year by airplane, and they feel the emotion of maybe having to give that up (...), they descend into this grief, loss situation; and the only way to rise out of that is to feel virtuous and to tap into some universalist values. (...) that's just my observation of what seems to happen with people' (F-18). Many participants described how taking part in Carbon Conversations encouraged them to reflect on their values. While only two interview participants $(\mathrm{CC}-11 ; \mathrm{CC}-22)$ thought they had quite fundamentally changed their values or even 'become a different person' (CC-11) after taking part, many others felt the initiative had 'reinforced' (e.g. CC-8, CC-2, CC-3, CC15) some of the values that they had held before but not 'lived by them' (CC-5).

Among some participants, the reinforcement of supportive values encouraged radical behaviour changes such as giving up or reducing flying, giving up meat, avoiding supermarkets and consuming less. For instance, Lynn (CC-6) started to travel to Europe by train rather than plane after taking part and stated that she sympathised with the idea of travelling more slowly 'to feel the land, to feel the travel to get to a place you want to go to, so that's all part of the journey'. Later in the interview, she states that Carbon Conversations ...

'made me slow down. I was going too fast and I've been going too fast for too long, and I was losing sight of the things that were important to me. (...) it's that kind of looking again at what's important to you and making time for the things that are important rather than trying to live life too fast' (Lynn, CC-6).

It is reasonable to assume that there is a connection between Lynn's re-appreciation of slower forms of travel and her consideration of her pace of life and what is important to her.

Similarly, Peter explained how the group discussions helped him re-connect with some of his values which then supported behaviour change:

'Well it's the kind of seeds that makes you think about it and then as you start thinking about it then you talk about it a bit more and you kind of shape your opinion and your perception of what you want to do (...). So, for instance, I have never really liked big chains like Sainsbury's and stuff like that but never really made a conscious choice, whereas now, even though it takes a bit of 
time, you know, (...) now I make a conscious choice (...), apart from Lidl I just avoid supermarkets as much as I can' (CC-3).

In these two examples, re-considering values supported behaviour change. However, some forms of consumption to which participants were emotionally attached proved more difficult to shift, especially going on holidays abroad (CC1, CC-11) or 'love miles' by plane to visit close family members overseas (e.g. CC-15, CC-8). For example, Anabel (CC-1) considered holidays abroad as too important to be given up, mainly because of the 'crappy summer' in the UK, 'and that's, that will keep me going (laughing)'. The 'love miles' example illustrates even more clearly how difficult personal change can be if priorities are in conflict. For instance, Mary (CC-15) explains how difficult she finds it to reduce plane journeys, especially to visit other family members: 'it's an internal dialogue of great discomfort but it's not, it's not uncomfortable enough yet for me to do anything about it (...) one of these days I'll change but I'm not changing yet'. Here, reflection on intense inner conflicts was not sufficient to shift behaviours, partly because Mary prioritised her values around family and caring for others over those for the environment.

One participant, George (CC-4), also mentioned that another member of his group who had a large swimming pool and a high carbon lifestyle had left the group before completion. According to George, that other participant 'was very emotional about that' but 'didn't see a way around that'. This example again indicates that there are limitations for Carbon Conversations to engage people with high carbon lifestyles and identities.

These limitations also surface in discussions around guilt. Creating a safe, non-judgemental atmosphere is at the heart of Carbon Conversations which, for facilitators, involves trying not to make participants feel guilty 'about things that they can't affect' (F-2). At the same time, this facilitator acknowledged the dilemma that 'you need to actually make sure they don't use that to kind of just slip away from ever doing anything' (F-2). Indeed, some participants appeared to interpret the non-judgemental approach as an excuse to continue certain practices, most vividly expressed by Anne (CC-13) who felt the group had 'allowed her' to have her power shower, 'because it wasn't judgemental'. This illustrates that facilitation requires high levels of skill to balance these discussions around guilt.

Several facilitators also acknowledged that personality, social norms, group dynamics and other factors can influence the extent to which participants are willing and able to sense and reflect on their own emotions and engage in more personal discussions with others, and that 
this can subsequently influence how well or not the group is able to encourage participants to engage more with climate change.

\section{Discussion and conclusions}

The results from this research show that addressing difficult emotions around climate change and personal carbon reduction can play an important role for third sector initiatives working in this field. We found evidence that the third sector initiative Carbon Conversations which encourages participants to reflect on and share emotions and inner conflicts in relation to climate change and personal carbon reduction with others has helped many participants to engage with these issues more deeply and take, sometimes quite radical, carbon reducing actions in multiple areas. However, the material suggests that Carbon Conversations has different things to offer to different audiences: it seems to work best for participants who have at least a vague interest in climate change but have not yet engaged very deeply with the issues or with personal carbon reduction. Several participants who could be described in this way reported that Carbon Conversations had helped them learn more about climate change, reconsider what is important to them and, often, change their behaviours. Many confirm that group support and sharing experiences and emotions played an important role in this process. In comparison, participants who had already extensively engaged with climate change and had, often radically, reduced their carbon footprints before the course usually reported fewer or less radical changes to their awareness or behaviours. That said, they still found the group environment helpful for moral support and reinforcement of what they were doing. Several participants also report that taking part made them feel more confident in talking to and encouraging people in their personal networks to reduce their emissions, indicating that the impact of Carbon Conversations may extend beyond the direct participants. Overall, these findings support arguments made in the literatures on the psychology of climate change (Norgaard 2006, Hamilton 2010: 118-33, Dodds 2011: 41-55, Weintrobe 2013) and the role of groups for personal change (Whitaker 2001: 55, Brown 2011: 244) and contribute new insights to our understanding of the role of third sector organisations in climate change engagement. Important lessons can be drawn for initiatives in this field: awareness amongst organisers of emotional processes related to climate change engagement can be important to develop more effective ways of engaging different audiences. The provision of information on climate change, especially if it induces fear and seeks to shock people into action, is likely to be ineffective if insufficient room is provided for audiences to express and discuss their 
responses to this information with others. Behaviour change advice without attention to inner conflicts that are linked to identities and values is also likely to be less effective in the long term.

We end with some considerations of the limitations faced by initiatives such as Carbon Conversations. The most obvious is one that has emerged on a number of occasions in this paper: initiatives such as Carbon Conversations tend to attract the already engaged; or at best those already sympathetic towards consideration of climate change. While we have shown that it can help these audiences engage more deeply with climate change, the need to reach out to those who are disinterested, especially those with high carbon footprints, remains a key challenge for these initiatives. Second, the success of Carbon Conversations in dealing with emotions and group dynamics is intimately tied with skilled facilitation. While there will always be differences in skills and capacities, the training and support for facilitators ensures that they are reasonably well-prepared for what can be a challenging (in both senses of the word) role. Third, our evidence supports the claim made by advocates of Carbon Conversations that participants' sharing their experiences can help them and others become more aware of and reflect on their feelings and inner conflicts (rather than assuming that there are 'affects' that will always remain unconscious (e.g. see discussion in Pile 2010)). However, it needs to be acknowledged that people's willingness and capacity to sense, reflect on and express their emotions varies: some people are likely to be more susceptible to such processes of reflection and thus more likely to participate in initiatives such as Carbon Conversations, or experience them positively, than others. Fourth, there are reasonable questions as to whether six meetings are enough to fully explore the emotions associated with climate change and personal change: does more sustained and radical behavioural change require longer engagement and support? This relates to a fifth consideration: compared to some other carbon reduction initiatives, Carbon Conversations is more resource intensive in terms of time commitment and facilitator training. That said, the 'cost/benefit analysis' may be in Carbon Conversation's favour if the behaviour change that it prompts is deeper and longer lasting. To better understand such questions will require a more intensive, comparative and longer-term research design that compares Carbon Conversations to other initiatives and includes actual (before, after and long-after) behaviours rather than reported. Research in this area also faces specific challenges as it is difficult to establish a level of trust within an interview situation that allows participants to speak openly about their emotions and inner conflicts. A more longitudinal study design could partly address this issue. Finally, it is important to remind ourselves that while Carbon Conversations facilitates 'inner change' required for more 
meaningful engagement with climate change, it does little to challenge the socio-technical structures that reinforce high carbon travel and consumption patterns (Shove et al 2012).

Acknowledgements: This research was funded by the Third Sector Research Centre (ESRC; Cadbury Trust; Office of Civil Society), RES-595-28-0001. Many thanks to Rebecca Edwards who was involved with collecting data for this project in its early phase; to Ro Randall, Anthony Armitage at COIN and Pamela McLean at The Surefoot Effect for making this research possible, to all of our interviewees for sharing their experiences and giving their time so generously, and to the anonymous reviewers for helpful comments on an earlier version of this paper.

\section{References}

Barnes, M. 2008. 'Passionate participation: Emotional experiences and expressions in deliberative forums'. Critical Social Policy 28: 461-481.

Brown, N. 2011. Psychoeducational groups: Process and practice (3rd edition) London / New York: Routledge. Crompton, T., With Brewer, J., Chilton, P. \& Kasser, T. 2010. Common cause. The case for working with our cultural values. Woking: WWF-UK.

Davidson, S. 2010. 'Global action plans's ecoteams programme'. In Peters, M., Fudge, S. \& Jackson, T. eds., Low carbon communities. Imaginative approaches to combating climate change locally, 157-177. Cheltenham: Edward Elgar.

Dodds, J. 2011. Psychoanalysis and ecology at the edge of chaos London / New York: Routledge.

Georg, S. 1999. 'The social shaping of household consumption'. Ecological Economics 28: 455-466.

Habermas, J. 1984. The theory of communicative action, vol.1, reason and the rationalization of society Boston: Beacon.

Hale, S. 2010. 'The new politics of climate change: Why we are failing and how we will succeed'. Environmental Politics 19: 255-275.

Hamilton, C. 2010. Requiem for a species London / Washington, D.C.: Earthscan.

Heiskanen, E., Johnson, M., Robinson, S., Vadovics, E. \& Saastamoinen, M. 2010. 'Low-carbon communities as a context for individual behavioural change'. Energy Policy 38: 7586-7595.

Hobson, K. 2003. 'Thinking habits into action: The role of knowledge and process in questioning household consumption practices'. Local Environment: The International Journal of Justice and Sustainability $\mathbf{8}$ : $95-112$.

House of Lords 2011. Behaviour change. Science and Technology Select Committee, 2nd Report of Session 2010-12, July 2011, London : The Stationery Office.

Howell, R.A. 2012. 'Living with a carbon allowance: The experiences of carbon rationing action groups and implications for policy'. Energy Policy 41: 250-258.

Howell, R.A. 2014. 'Investigating the long-term impacts of climate change communications on individuals' attitudes and behavior'. Environment and Behavior 46: 70-101.

Jones, R., Pykett, J. \& Whitehead, M. 2014. 'The geographies of policy translation: How nudge became the default policy option'. Environment and Planning C-Government and Policy 32: 54-69.

Lertzman, R.A. 2013. 'The myth of apathy: Psychoanalytic explorations of environmental subjectivity'. In Weintrobe, S. ed. Engaging with climate change. Psychoanalytic and interdisciplinary perspectives, 117-133. London / New York: Routledge.

Lewin, K. 1947. 'Frontiers in group dynamics: Concept, method and reality in social science; social equilibria and social change'. Human Relations 1: 5-41. 
Meijnders, A.L., Midden, C.J.H. \& Wilke, H.a.M. 2001. 'Role of negative emotion in communication about co(2) risks'. Risk Analysis 21: 955-966.

Middlemiss, L.K. 2008. 'Influencing individual sustainability: A review of the evidence on the role of community-based organisations'. International Journal of Environment and Sustainable Development 7: 78-93.

Norgaard, K.M. 2006. "'People want to protect themselves a little bit": Emotions, denial, and social movement nonparticipation'. Sociological Inquiry 76: 372-396.

Nye, M. \& Burgess, J. 2008. Promoting durable change in household waste and energy use behaviour. Report, University of East Anglia.

Nye, M. \& Hargreaves, T. 2010. 'Exploring the social dynamics of proenvironmental behavior change'. Journal of Industrial Ecology 14: 137-149.

O'neill, S. \& Nicholson-Cole, S. 2009. "'Fear won't do it" promoting positive engagement with climate change through visual and iconic representations'. Science Communication 30: 355-379.

Owens, S. \& Driffill, L. 2008. 'How to change attitudes and behaviours in the context of energy'. Energy Policy 36: 4412-4418.

Pile, S. 2010. 'Emotions and affect in recent human geography'. Transactions of the Institute of British Geographers 35: 5-20.

Randall, R. 2009. 'Loss and climate change: The cost of parallel narratives'. Ecopsychology 1: 118-129.

Randall, R. 2013a. Carbon conversations. Six meetings about climate change and carbon reduction. Facilitator's guide (revised ed.). Stirling: The Surefoot Effect.

Randall, R. 2013b. 'Great expectation: The psychodynamics of ecological debt'. In Weintrobe, S. ed. Engaging with climate change. Psychoanalytic and interdisciplinary perspectives, 87-102. London / New York: Routledge.

Randall, R. \& Brown, A. 2013. Carbon conversations. Six meetings about climate change and carbon reduction (revised ed.). Stirling: The Surefoot Effect.

Smith, G. 2003. Deliberative democracy and the environment London / New York: Routledge.

Staats, H., Harland, P. \& Wilke, H.a.M. 2004. 'Effecting durable change: A team approach to improve environmental behavior in the household'. Environment and Behavior 36: 341-367.

The Guardian 2009. The manchester report: 20 ideas for solving the climate crisis. 13 July 2009.

Weintrobe, S. 2013. 'The difficult problem of anxiety in thinking about climate change'. In Weintrobe, S. ed. Engaging with climate change. Psychoanalytic and interdisciplinary perspectives, 33-47. London / New York: Routledge.

Whitaker, D. 2001. Using groups to help people (2nd ed.) London: Routledge. 